\title{
PENSAMIENTO ESPAÑOL: UNA CATEGORÍA HISTORIOGRÁFICA
}

\author{
José Luis ABELLÂN \\ Universidad Complutense de Madrid
}

Desde que en 1876 la fogosidad juvenil de Menéndez Pelayo plantea la famosa polémica de la ciencia española - centrada a poco de empezar sobre la cuestión filosófica - ha venido discutiéndose durante casi un siglo sobre la existencia o inexistencia de una filosofía española. No hay tratado o libro sobre la Historia de la filosofia española que no plantee en el prólogo inicial dicha cuestión, contestándola en la forma que más oportuno le parezca al autor. La mayoría de esas contestaciones, sin embargo, han sido positivas: todas $\longrightarrow$ casi todas- dan por supuesta la existencia de filosofía en España, si bien matizando la afirmación convenientemente. Es evidente que la filosofía en Espana ha ido adquiriendo un estatuto especial, de acuerdo con los condicionamientos de su desarrollo histórico. Es éste el tema que trataremos de clarificar aquí.

El punto central de la cuestión tiene necesariamente que remitirse a la concepción canónica de la Historia de la Filosofía, tal como quedó formulada a mitad del siglo XIX por los alemanes. Surge dicha concepción en su formulación científica como el resultado de la convergencia entre dos movimientos aparentemente opuestos: el idealismo y el positivismo. Del primero, toma los conceptos de Entwicklung y Aufhebung para elaborar un concepto de historia que, asumiendo el método dialéctico, se presenta como ordo et conexio idearum y, en consecuencia, privilegia el sistema filosófico como objeto de su ocupación. Del segundo, aprovecha los adelantos de la filología que, con sus secuelas - crítica de fuentes, detección de interpolaciones, ediciones fiables-, nos ofrece textos filosóficos depurados y auténticos con los que poder operar rigurosamente. El resultado es una concepción científica de la historia de la filosofía donde los sistemas filosóficos adquieren protagonismo en detrimento tanto 
de los autores que no han desarrollado sistemas - Voltaire, Montesquieu, Nietzsche, Kierkegard,...- como de las tradiciones filosóficas en que lo sistemático ocupa un segundo plano: culturalistas, ametafísicos, inmanentistas o ensayistas; es el caso de la tradición oriental o de la española ${ }^{1}$.

Esta concepción canónica de la Historia de la Filosofía va a su vez a beneficiarse de lo que se ha llamado «el encuentro griego-alemán», iniciado con el gran desarrollo del romanticismo en aquel país - Goethe, Schiller, Hölderling, Rilke-y su vertiente filosófica a través del idealismo - Herder, Jacobi, Fichte, Schelling, Hegel- - Ha habido una tradición alemana de filosofía que se inicia a mediados del siglo XVIII con las investigaciones de Winckelmann y se prolongará durante toda la primera mitad del XIX con la obra de los grandes idealistas hasta configurar una tradición fuerte de la filosofía convertida en paradigma del quehacer filosófico. Esa tradición fuerte -que tiene como eje su inspiración en el mundo helénico- se va a identificar con la de los grandes sistemas a que nos hemos referido en el párrafo anterior. Ambas tradiciones unidas se convierten en el núcleo duro de toda Historia de la Filosoffa canónicamente concebida.

En el marco dibujado se inician los intentos de configurar una historia de la Filosofía Española con dos condicionantes muy claros. Por un lado, esa concepción científica de la Historia de la Filosofía desarrollada a mediados del siglo XIX y cuyas coordenadas acabamos de exponer. Por otro lado, el impulso nacionalista que invade Europa durante el siglo XIX y, sobre todo, a raíz del movimiento revolucionario del 48, punto de arranque de la llamada "primavera de los pueblos" (Völkerfrübling). En Espana la ola nacionalista tiene varias consecuencias: una de ellas es el desarrollo del iberismo como movimiento progresista que tiene como fin la constitución de una "Unión ibérica" en la que Espańa y Portugal queden integrados; otra consecuencia es el impulso dado por la opinión política del "moderantismo" al llamado nacionalismo de la "nación española" que se traduce en el nuevo género historiográfico de las llamadas historias generales. José María Jover define éstas no como un relato aséptico de los hechos, sino como aquellas en que uel narrador proyecta, sobre las grandes encrucijadas que jalonan la trayectoria de su protagonista, unos crite-

1 Un desarrollo pormenorizado de la cuestión tratada puede verse en el libro ¿̨xiste una filosofia española?, Fundación Fernando Rielo, Madrid, 1988, donde aparece una contribución mía con este título: «¿Existe la filosofía espanola?. Razones de un pseudoproblema». 
rios valorativos de raíz especialmente nacional, que subrayan la continuidad de un Volkgeist, unas veces en posición triunfante y otras ominosamente doblegado; en fín, la historia general no es una historia de eruditos destinada a eruditos, ni un tratado universitario, sino una especie de biblia secularizada, de libro nacional por excelencia, llamado a ocupar un lugar preferente en despachos y bibliotecas de las clases media y alta" ${ }^{2}$. Un complemento enriquecedor de dicha historia sería, en este contexto, la elaboración de una Historia de la Filosofía Española con carácter propio y específico.

Ese es, en definitiva, el intento de Menéndez Pelayo, siguiendo las directrices de su injustamente olvidado maestro, Gumersindo Laverde, y es ello también lo que explica en parte el interés de ambos en enfatizar los caracteres nacionales de su proyecto de Historia de la filosofía española, insistiendo en la unidad de la patria y su católica esencia. Adolfo Bonilla y San Martín, que siguió el impulso dado a la disciplina por su maestro Menéndez Pelayo, rebajará las directrices nacionalistas imprimidas al proyecto por sus antecesores, tratando de encauzarlo dentro de la orientación científica que habían dado a la disciplina de Historia de la Filosofía los pensadores alemanes. Así surgí el Plan de una Historia de la Filosofia Española ${ }^{3}$, que ha tenido vigencia hasta tiempos recientes, sirviendo de inspiración a lo que nosotros llamamos en su momento Corpus sistemático de la Historia de la Filosofia Española, donde además del propio Bonilla han colaborado los hermanos Carreras Artau, Marcial Solana y Miguel Cruz Hernández. Con todo, y como es sabido, el proyecto no alcanzó más allá del siglo XVI, lo que implícitamente supone el fracaso de su realización, situación que hay que achacar a una razón fundamental: se han utilizado para escribir la historia de nuestra filosofía criterios y métodos válidos para la historia universal de la filosofía, pero que, aplicados a nuestra realidad, acaban por desvirtuarlo, desenfocarlo y tergiversarlo.

El «estado de la cuestión» en la disciplina nos sitúa ante una conclusión bien acreditada: existe una historia de la filosofía española, lo que a estas alturas no se puede negar, pero es evidente a su vez que su configuración no res-

2 José M.a JOVER, "Caracteres del nacionalismo espaniol, 1854-1874", en Posibilidades y limites de una historiografia nacional Sociedad Görres, Simposio Germano-Español, Madrid, 8 a 12 de marzo, 1983.

3 Está publicado en la Memoria de la Escuela de Estudios Superiores del Ateneo de Madrid, para el curso 1904-1905; págs. 13-27. El mismo Plan se halla incluido también, con ligeras modificaciones, en Historia critica del pensamiento españoh tomo I, Madrid, 1979, págs. 359-370. 
ponde a lo que hemos llamado la concepción canónica de la Historia de la Filosofia, donde el sistema filosófico ha quedado privilegiado hasta convertirse en protagonista casi único. Es esta configuración de su historia lo que ha dado a la palabra "filosofia" un sentido fuerte que no se ajusta al desarrollo de la nuestra en el contexto español; de aquí mi propuesta de sustituir, a la hora de estudiar nuestra historia filosofica, la palabra "filosofia" por la de "pensamienton, más acorde con el desarrollo histórico español. Así lo he hecho en los distintos libros publicados con el denominador común de Historia del Pensamiento.

Mi propuesta de recuperar la categoría "pensamiento espańol" como propia y específica de nuestra filosofía tiene ya un precedente clarisimo en la obra del filósofo José Gaos, que en su Antología del pensamiento en lengua española en la Edad Contemporánea (México, 1945) realiza dicha reivindicación. En la introducción a esta obra, que ya por el mismo título resulta significativa, destaca Gaos como del mismo hecho de significarse y expresarse en una lengua el pensamiento adquiere una unidad que viene dada por ella, puesto que la lengua da unidad al pensamiento en ella expresado. Al mismo tiempo, y al hacer hincapié en el pensamiento llamado de la decadencia en España y de la independencia en América, resalta las "notorias afinidades de fondo y forma» entre ambos.

Al hacer el análisis de las citadas afinidades, Gaos deja a un lado el llamado pensamiento de la grandeza, que se corresponde con los primeros siglos de la Edad Moderna. En esa época, el pensamiento centrado en el descubrimiento, conquista y colonización de América, mantiene la unidad que proviene del Imperio en que metrópoli y colonias se aglutinan. Es precisamente después al producirse la emancipación de éstas- cuando podría pensarse en una divergencia; se comprueba, sin embargo, que no es así al constatar que buscar las causas y encontrar los remedios de la decadencia nacionales son operaciones políricas del mismo sentido que poner las bases de la independencia nacional y resolver los problemas de su constitución y reconstitución como patrias libres y autónomas. Además, ocurre que ese pensamiento común se desarrolla también a través de unos mismos géneros literarios; lo expresa así Gaos: «En cuanto a la forma, la del tratado o curso sistemático y metódico es la de la parte también menos original, más meramente didáctica, de la obra colectiva; la de la parte más original y valiosa es la del ensayo y el artículo y la del discurso, de estilo de valor estético en muchos casos, sumo en algunos; los más grandes pensadores de lengua espanola desde el siglo de oro de las letras espanolas son precisa y sig- 
nificativamente los más grandes prosistas desde el mismo siglo. Por estas analogias de fondo y forma es por lo que pensamiento de la decadencia y de la independencia es más, o mejor, pensamiento que filosofia» (págs. XXV-VI).

La categoría "pensamiento" resulta, pues, especialmente apta y apropiada a la hora de exponer y analizar el decurso filosófico tanto de España como de los países iberoamericanos, y es esto precisamente lo que hace de la Historia de las ideas una metodología privilegiada para su estudio. A su desarrollo he dedicado algunos de mis esfuerzos personales más persistentes, haciendo ver como sus planteamientos se enriquecen extraordinariamente cuando conseguimos que la disciplina se beneficie de las grandes aportaciones de las Ciencias Sociales -Psicología, Psicoanálisis, Antropología Cultural, Sociología del Conocimiento- que aplicadas al estudio de la génesis del pensamiento resul$\tan$ enriquecedoras y esclarecedoras.

Me llamó la atención en su día el comprobar que ese desarrollo metodológico venía a coincidir con una concepción de la Historia de la Filosofía defendida por Ortega y Gasset en cuanto se vinculaba ésta a las "circunstancias" históricas y existenciales en que la misma se producía. Así establece el filossofo espafol una "nueva filologia para la cual la idea es una acción que el hombre realiza en vista de una determinada circunstancia y con una precisa finalidad" ${ }^{4}$, llegando a definir el pensar como un "dialogar con la circunstancia", lo cual implica a su vez una profunda revisión de lo que es la historia de la filosofia; he aquí un resumen de su posición:

"No basta para creer que se hace historia mostrar la influencia que una idea anterior ha tenido en una posterior. Esto es pura metáfora. Una idea de ayer no influye en otra de hoy, propiamente hablando, sino que aquélla influye en un hombre que reacciona a esa influencia con la nueva idea. Es en vano querer hacer historia si se elude hablar de hombres y colectividades de hombres. En suma, que la historia de la filosofía deberá anular la presunta existencia deshumanizada en que nos ofrece las doctrinas y volver a sumergirlas en el dinamismo de la vida humana, mostrándonos su funcionamiento teleológico en ella. ¡Imagínese que de pronto todas esas ideas momificadas e inertes que la tradicional historia de la filosofía nos propone,

4 José Ortega y Gasset, "Ideas para una Historia de la Filosofía», Obras Completas, Madrid, 1983; tomo VI, pág. 162. 
entrasen en resurrección, que comenzasen a vivir, esto es, a ejercer su función, a cumplir su papel en la existencia de esos hombres que las pensaron! Ipso facto todas esas extrañas combinaciones de ideas se iluminarían en una universal 'evidencia', es decir, que al hacernos sus historiadores las reviviriamos e imaginariamente nos satisfarian como satisficieron a sus creadores y a los que les siguieron como discípulos y adictos» ${ }^{5}$.

Según esta concepción de la historia de la filosofía, lo que interesa en ella no son las doctrinas abstractas, sino la función que realizan en un determinado momento en la economía personal del filósofo y/o de la sociedad en que éste vive. Naturalmente, esto lleva ipso facto a ocuparse con las circunstancias nacionales en que una filosofía nace y, por tanto, a justificar epistemológicamente la ocupación con las filosofías nacionales de un país - por ejemplo, España - o las supranacionales de una determinada sociedad - comunidad de los países latinoamericanos-, lo que indudablemente viene a cambiar el estatuto epistemológico de la Historia de la Filosofía, con importantes consecuencias, como las que veremos a continuación.

La primera está clara. Tras todo lo expuesto en páginas anteriores parece haber pocas dudas de que la palabra "pensamiento" es expresión de una categoría historiográfica que mantiene similitudes y concomitancias con la «filosofia", aunque, en definitiva, sea distinta de ella, sobre todo si la empleamos en el sentido fuerte que ha impuesto la concepción canónica tradicional de la Historia de la Filosofía. Por lo demás, también parece claro que esa categoría resulta especialmente apta para dar cuenta y razón de la Historia de la Filosofía Española, con lo que ésta aparecerá como Historia del Pensamiento. Al hacerlo así en la práctica de nuestras investigaciones, hemos resuelto la vieja aporía sobre la existencia o no de una historia española de la filosofía, ya que la nueva categoría exige aplicar una nueva metodología - la de la Historia de las ideas - adecuada a su objeto. Con ello creo que ponemos fin a un siglo y medio de debate teórico. Es evidente que existe una Historia de la Filosofía Española, aunque ésta tenga que tomar la forma de Historia del Pensamiento. Así llegamos al fin del siglo XX con la conclusión muy clara de que hemos contribuido decisivamente a la consolidación y asentamiento de tan controvertida disciplina.

5 Ibid., pág. 165. 
La segunda consecuencia de esta nueva visión de la Historia de la Filosofía no resulta menos importante. Me refiero al valor metodológico de la Historia de las Ideas para un acercamiento intercultural al proceso actual de globalización, lo que resulta imprescindible no sólo para el adecuado conocimiento de las distintas tradiciones históricas, sino para el proceso de convivencia mundial en la marcha hacia la integración global. Esto, naturalmente, supone haber profundizado en las leyes e implicaciones de la interculturalidad, lo que no es éste el lugar para su debido desarrollo; bastenos aquí aludir al fundamento de la misma: la necesidad de atenernos, en la esfera de la cultura, a una ley ecológica equivalente a la de la biodiversidad en la esfera de la naturaleza, lo cual nos abocará irremisiblemente a una revolución filosófica en la que se esclarezcan los principios de la interculturalidad a la luz de una nueva lectura de la dialéctica identidad/diferencia, basada en un pensar el ser desde esta última. Defender y respetar la diferencia sin destruir la identidad de la especie humana: he aquí el gran reto que nos aguarda inquietante y angustioso durante el siglo XXI. Afrontarlo exigiría un desarrollo adecuado de los principios de la interculturalidad, que se puede ver muy beneficiado de una meditación sobre el pensamiento español como categoría historiográfica. Ese desarrollo sería demasiado largo y complejo para realizarlo aquí, pero no cabe duda que es una tarea imperiosa para el inmediato futuro de nuestra civilización. No lo demoremos.

Escorial, 28 junio 99. 